\title{
Research on the Risk Oriented Internal Audit under the Informatization Environment
}

\author{
Xiaoyun Yan \\ Guangdong University of Science \& Technology, Dongguan, China
}

Keywords: Informatization, Risk oriented, Internal audit, Accounting

\begin{abstract}
The risk management of internal auditing under the informatization environment needs to establish a modern risk oriented model focusing on the electronic data test and the significant error risk assessment, so that it can better understand the composition of the audit risk effectively control audit risks. Based on the author's study and practice experiences, this paper first analyzes the backwardness of internal control system under the informtization environment, second studies the problems faced by the internal audit under the informatization environment, third discusses the risk elements of internal audits under the informatization environment, finally, it puts forward the risk management and prevention measures of internal audit under the informatization environment.
\end{abstract}

\section{Introduction}

Informatization is characterized by using information technology, developing information resources, sharing information and knowledge. With the increasing development of information technology, the environment of enterprises and institutions environment is also becoming more and more networked and informationalized. Compared with the traditional audit, there are many differences between the audit target, audit object and the method in the informatization audit. Therefore, how to carry out risk assessment and control under the informatization environment has become a new trend of internal audit.

\section{The Backwardness of the Unit Internal Control System under the Informatization Environment}

The importance of informatization internal control has not been fully recognized. After the implementation of accounting informatization, some of the internal control measures under the manual accounting system are transferred to the computer, and the measures are automatically completed by the computer. In this way, internal control measures of information system is divided into two parts: general control based on organizational measures to organize and application control based on computer system program control, also the control mode is changed from manual control to computer control, and is combined with manual control. Due to data processing is centralized, the consolidation of duties is serious, and accounting personnel are greatly reduced, so that some incompatible duties can not be separated, which may make them modify and operate the programs and database in use without being authorised and the accuracy and security of accounting data are threatened.

Defects of input and output control. Under the environment of informatization, program and data are stored together, the form of data input and output is different from manual accounting system. The input of the data may lack sufficient and reliable records, some data without being confirmed do not have attachments may also be entered into the system, resulting in the distortion of the output information; In terms of output, it often relies on electronic computers to access data which are stored in magnetic media. And stored or changed data and procedures are concentrated in the same device, if there is no appropriate control, it is possible to access or change the data without authorization.

Potential threats to data processing and preservation. The subject of execution of accounting information system is the computer, if the computer hardware system fails or the power fails and has other non-human factors, it will cause the data can not be processed and the accounting business 
operation will not be able to carry out. Also the quality and performance of financial software will affect the accuracy and efficiency of accounting data processing. Because the forms data under the accounting informatization environment are mainly typed account tables and accounting data stored on computer disks or external floppy disks, once these magnetic medium are damaged because of high temperature, damp and abrasion, the saved data will not be read. If there is no good corresponding backup, it will seriously affect the enterprise's accounting work.

\section{Problems of the Internal Audit under the Informatization Environment}

The evidence of paper audit reduces, update speed of information technology is fast, and the auditors have difficulty in mastering and applying. Under the environment of informatization, paperless data and paperless transactions reduce the repeated input and repeated processing of data, and also lead to the routinization of accounting treatment. After the occurrence of businesses, as long as the operations officer implement the corresponding function, accounting personnel can directly record businesses to the corresponding accounts without filling in the certificates, the internal control of system relies more on its own real-time control. So the reliability of data, the reduction of the original paper audit evidence, the change of internal control system become problems internal audit must face. Furthermore, under the computerized environment, audit evidence mostly being stored in the database, the traditional auditing technology is difficult to reach the goals, and it must continues to adopt new technologies and means of audit, such as the use of test procedure for embedded system to complete audit of important treatments, the collection and analysis of audit software to handle audit data, the use of dynamic software to track changes in some important data.

The increased difficulties of the internal control system audit. Under the informatization environment, internal control makes great changes. Some internal control measures under the original manual processing environment are canceled because of losing the functions, some internal control measures play a role after the execution of software programs, and at the same time, according to the characteristics of information system, a number of new internal control measures are increased. Because of the continuous development of internal control technology, how to understand, test, and evaluate the internal control of information system has become a difficult problem of internal audit. At the same time, the system integration has also changed the management mode of each unit. Because the information system can use the hinder treatment result to cover the front result without leaving any traces, the difficulties of the integrity and reliability of internal audit evaluation data are increased.

The professional knowledge and the computer levels of auditor lay behind. The application of network and the realization of comprehensive informatization change that kind of singe and independent business model at the beginning of computerization, enterprises and institutions reorganize businesses and restructure business processes in accordance with the principle of high-efficiency. The integration of business data, financial data, business process and financial management makes the mutual fusion of management audit and financial audit,and virtually expands the scope of audit, improves the difficulties of the audit and the auditor's professional knowledge requirements.

The factors of internal audit risk under informatization environment. Informatization environment makes the audit objective is no longer expressing views on the financial statements singly, but presents a trend of diversification, it includes both the audit of conventional financial statements' legitimacy and fairness, and the needs to audit the safety and reliability of the network information system. Multiple audit objectives put forward higher requirements to the internal audit work -- facing the new working environment, the complexity of the audit objects, and the change of audit methods. These all indicate that under the informatization environment, internal auditors face more uncertain factors, audit risk elements also have the very big changes, and this risk factors will vary with the change of information technology. Furthermore, under the condition of informatization, business unit systems and financial systems all be placed in the open environment, most business activities change from the original traditional transactions to the transactions and 
settlements through the internet, and it requires the financial system of transaction processing being based on the electronic data with no trace, based on real time network financial software as the main means of accounting treatments, all of these make the unit data systems face the dual interference of both system and non system factors (i.e. traditional risk factors), these risk factors are divided into internal factors and external factors by their sources. Risk factors are shown in figure 1.

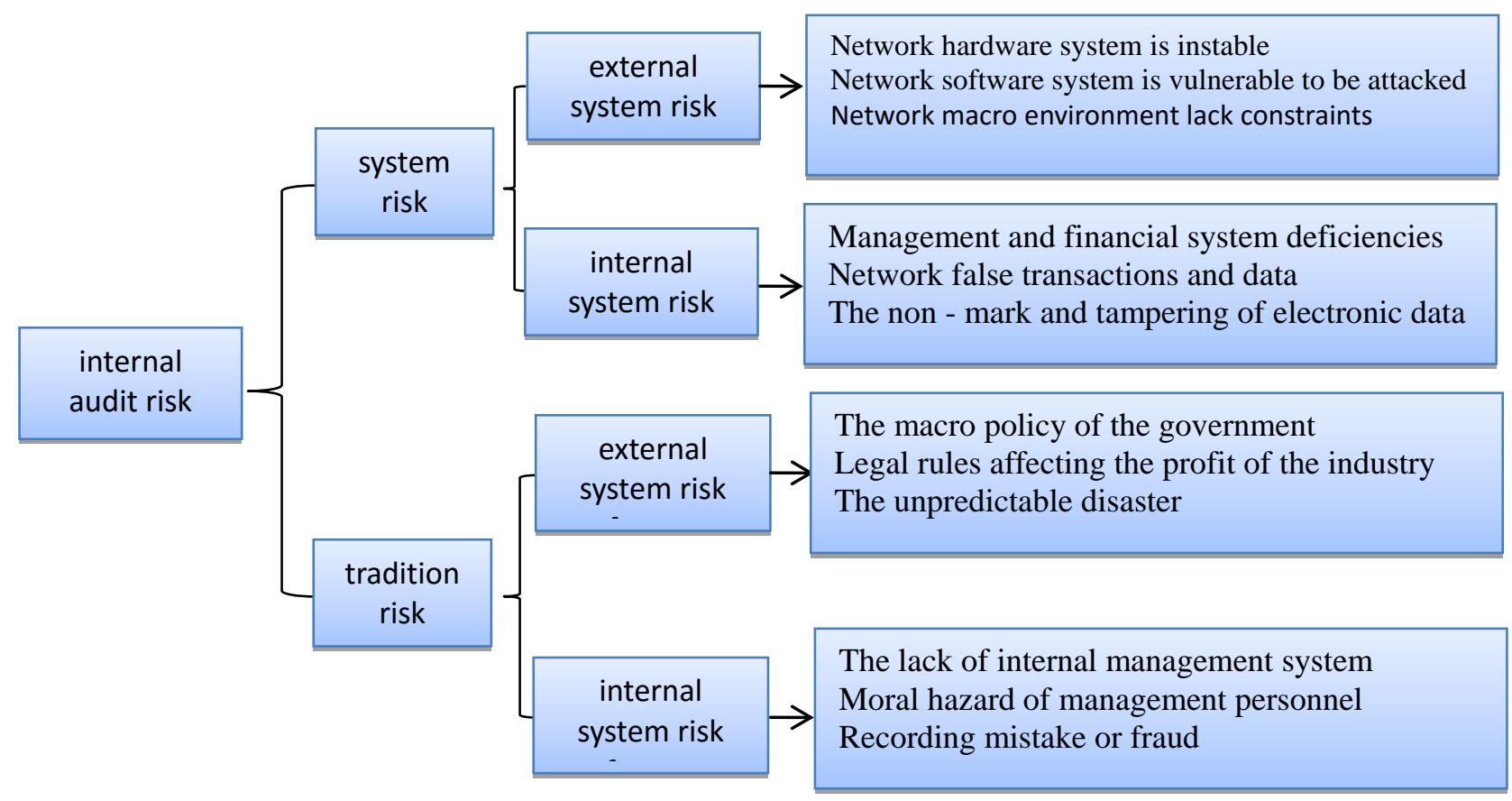

Fig.1 internal audit risk factors in the informatization environment

\section{Internal Audit Risk Management and Preventive Measures under the Informatization Environment}

Strengthen and improve the internal audit system under the informatization environment. In the computer network system, the form of data processing is the "man-machine" dialogue, which puts forward higher and stricter requirements to the internal audit. Internal audit is the activities of managing functions on integrative network, computer and information processing under the direct leadership of the supreme administrative person in charge, and supervising, inspecting, evaluating its legitimacy, authenticity, reliability and efficiency. Its main purpose is to protect the authenticity and reliability of management data generated by its units' computer management information systems, to ensure the safety of data transmission on the network, and to make an evaluation of the system security. Therefore, in all aspects of the operation of the information system, internal audit staff should be involved. They should regularly inspect and test the work of the accounting information system and participate in the development and supervision of the implementation of the relevant management systems. At the same time, the internal auditors should actively study the internal audit knowledge of accounting information system, and constantly improve their business level, so as to improve the effectiveness and efficiency of internal audit.

Focus on the implementation of the units' information system audit. At present, most units bypass the information system in the internal audit. Because of the massive reduction of original documents in the integrated system, the correspondence between data is fuzzy and the business process and the financial management are highly integrated, so that the data stored in the system may not be consistent with the output data. For example, relevant person transfer data by embedding illegal blocks into the system, provide the typed false data to the audit staff, which increases the audit risks. Therefore, if intern auditors want to understand the trustworthiness of data provided by system, they must audit the system itself, and the internal auditors must also have an understanding of the computer information system and the relevant situation, including: information 
system structure, memory capacity, input and output devices, communications equipment, auxiliary storage device, the use of the operating system, database management system and application system,etc. In the implementation of the audit, the focus of compliance testing should be the setting and compliance of the internal control system, and the information conversion rules defined in the system. For accounting, business integration system, each business occurred in units will automatically generate accounting records and enter the financial system according to the transformation rules defined by business personnel and financial personnel. The focus of audit now is not just generating a large number of duplicate documents, but checking out if the defined information conversion rules are correct and effective, whether comply with the requirements of the relevant laws and regulations, whether the management of these rules is effective.

Implement the detailed audit focusing on testing electronic data. The internal audit under the informatization environment not only makes the financial audit a part of itself, but also makes the financial audit method achieve real-time and focus on testing electronic data because of the function of system software. Since computer software can replace people to audit, which can make audit method changes from being oriented to the sampling audit to detailed audit. Of course, this detailed audit approach is more different from the detailed audit methods of early oriented audit mode. Under the informatization environment, auditors do not need to determine the focus of the audit from the reports, inverse back to vouchers, but to use real-time audit system to collect, arrange and transfer units' original electronic financial data, soon generate new books and financial statements and other financial information to compare the relevant financial data, and realize the verification of the financial data very conveniently. Therefore, except coming to the scene to monitor the audit and observe the actual business process under certain conditions, the financial audit under the informatization environment needs to transfer to the detailed audit focusing on testing electronic data, so that achieving the goal of reducing the audit risks.

\section{References}

[1] Yang Aiqun. Discussion of the application of risk oriented internal audit in enterprise risk management [J]. Modernization of Market, 2007,04:163-165.

[2] Xu Yuanling. Application of risk oriented internal audit [J]. Accounting Research, 2008,07:72-74.

[3] Li Juan. Analysis of risk oriented internal audit in colleges and universities [J]. Journal of Anqing Teachers College (SOCIAL SCIENCE EDITION), 2013,01:31-34.

[4] Miu Qijun. Research on risk oriented internal audit in colleges and universities [J]. Friends of Accounting, 2015,03:121-124.

[5] Guo Xiangyou. Construction of the competency model of audit staff under the risk oriented internal audi t [J]. Enterprise Guide, 2009,01:69-71.

[6] Li Zhen. Development and application of risk oriented internal audit [J]. New Economy, 2014,08:112-113. 